\title{
EXPERIÊNCIA E REPRESENTACCÃO DO ABANDONO E DO ARRUINAMENTO DO BAIRRO JARAGUÁ EM MACEIÓ/BRASIL
}

\section{EXPERIENCE AND REPRESENTATION OF ABANDONMENT AND RUINING OF THE BAIRRO JARAGUÁ IN MACEIÓ/BRAZIL}

Gilcileide Rodrigues da Silva ${ }^{1}$

UFAL: https://orcid.org/0000-0003-4626-8689

DOI: $10.21680 / 1982-1662.2021 v 4 n 31$ ID25390

\section{Resumo}

O estudo Geográfico de um recorte espacial, da cidade de Maceió, Estado de Alagoas (BR), versa acerca do abandono e do arruinamento dos espaços edificados. A finalidade consiste em entender como as pessoas experienciam e/ou representam o abandono e o arruinamento do bairro Jaraguá, institucionalizado como Zona Especial de Preservação Cultural. Apesar de ser uma zona de preservação cultural, os espaços em estado de abandono como casas, sobrados, armazéns e outras formas edificadas são perceptivos aos olhos do observador. A problemática nos instigou a entender: como as pessoas experienciam o abandono e o arruinamento? Assim, através de uma abordagem fenomenológica em Geografia, utilizou-se de narrativas de moradores e técnicos de órgãos públicos e privados situados no próprio bairro, para relatar suas experiências. Conclui-se que o abandono e o arruinamento são manifestados, enquanto um processo descontínuo, com evidências de um futuro incerto para aqueles que estão "ausentes" e presentes no bairro.

\footnotetext{
${ }^{1}$ E-mail: gilsilvaxxi@yahoo.com.br
} 
Palavras-chave: Abandono. Arruinamento. Experiência. Jaraguá.

\begin{abstract}
:
The geographic study of a spatial clipping, from the city of Maceió, State of Alagoas (BR), deals with the abandonment and ruin of built spaces. The purpose is to understand how people experience and / or represent the abandonment and ruin of the Jaraguá neighborhood, institutionalized as a Special Zone of Cultural Preservation. In spite of being a zone of cultural preservation, abandoned spaces such as houses, houses, warehouses and other built forms are perceptive in the eyes of the observer. The problem instigated us to understand: how do people experience abandonment and ruin? Thus, through a phenomenological approach in Geography, narratives of residents and technicians of public and private agencies located in the neighborhood were used to report their experiences. It is concluded that abandonment and ruin are manifested as a discontinuous process, with evidence of an uncertain future for those who are "absent" and present in the neighborhood.
\end{abstract}

Keywords: Abandonment. Ruin. Experience. Jaraguá.

\title{
Introdução
}

O abandono nos espaços edificados não é um fato recente; ganha expressividade teórica e conceitual, sobretudo nos últimos anos, uma vez que não está restrito a uma área específica do conhecimento. Ao contrário, consolida um campo de investigação interdisciplinar para compreender os processos ou eventos que têm levado diferentes ambientes construídos ao abandono e ao arruinamento. Para investigar os espaços edificados em abandono e/ou em arruinamento, delimitou-se como unidade espacial o bairro Jaraguá, da cidade de Maceió (AL), que apresenta características plausíveis do fenômeno.

A construção da análise do abandono pautou-se em uma abordagem fenomenológica em Geografia que busca examinar como as pessoas experienciam e/ou representam o abandono e o arruinamento do bairro Jaraguá, instituído como Zona Especial de Preservação Cultural da cidade. Não se trata de se obter novos 
conhecimentos empíricos acerca dos espaços abandonados, mas, de entender a relação básica do sujeito com o objeto, como um pressuposto de qualquer investigação empírica. Assim, ao invés de focar toda a atenção no objeto de estudo, esforçou-se para refletir, descrever e analisar as experiências intencionais contidas na relação do sujeito com o objeto (HUSSERL 1984 apud ZAHAVI, 2018).

A manifestação do abandono no bairro Jaraguá é o nosso caminho de aproximação com a realidade, dada a partir da experiência daqueles que mantêm uma relação com os espaços edificados em abandono. Os sujeitos participantes da pesquisa auxiliaram a investigar as possibilidades de experiência, de significado e de manifestação do fenômeno. Acrescenta-se, na constituição da análise, a compreensão dos conceitos de abandono e arruinamento para compor o quadro de inteligibilidade da investigação cientifica.

Mas, por que estudar o Jaraguá? Na verdade, foram observados os vazios de vivências nos espaços construídos, nas ruas com prédios em ruínas, armazéns (trapiches) abandonados, muitas moradias com placas de venda ou aluguel e pequenos comércios que abrem e logo fecham, sendo muitas das edificações heranças arquitetônicas do passado boêmio do bairro. E hoje nos causa inquietação em saber como conviver em um ambiente que parece que todos estão de passagem rápida, sendo que alguns já partiram há muito tempo, deixando como vestígio as ruínas e os espaços edificados sem vida.

É a partir dessa inquietação que a pesquisa começou a ser pensada para conhecer as manifestações do abandono e do arruinamento, considerando como fonte primária os relatos de moradores e técnicos de órgãos governamentais e não governamentais que estão na primeira Zona Especial de Preservação 1 (ZEP1), que foi regulamentada pela Lei n 4.545/1996 (MACEIÓ, 2006).

A representação dos espaços edificados é o testemunho de um passado, historicamente recente que alimenta a memória coletiva de um bairro portuário, que nasceu enquanto ancoradouro natural assumiu a categoria de freguesia do Jaraguá, antes mesmo de existir a cidade, até atingir um papel importante nas atividades comerciais, ainda na condição de vila, em volta de uma aldeia de pescadores.

As narrativas orais e escritas relacionam o declínio do bairro a um conjunto de fatores que ocorreram, tais como a modernização do Porto de Maceió (1940), desativação dos trapiches ou armazéns (1940); a retirada de todos os cabarés (1969); a 
queda da exportação do algodão (1980); e o abandono das famílias conservadoras. Esses fatores estão diretamente relacionados, de forma complexa, ao declínio.

Para além da paisagem do abandono, foi importante considerar o aporte teórico dos elementos que caracterizam de fato o abandono do imóvel, baseado nos estudos de Hiller et al (2003), Culhane; Hiller (2001) que definem determinados critérios para a investigação, como a funcionalidade do imóvel, a situação financeira e o estado físico, como forma de atestar o abandono. Desse modo, os registros das edificações foram obtidos na Prefeitura Municipal de Maceió, das ruas Sá e Albuquerque e Uruguai, além de serem verificados em campo, com anotações e registro fotográfico.

Para abordagem dos sujeitos da pesquisa acerca do abandono, as narrativas constituíram o principal instrumento, pois é bastante explícito ao focar tanto a dimensão temporal quanto a social de forma individualizada (ZAHAVI, 2017). Assim, percebeu-se que os eventos e as experiências que ocorrem em diferentes momentos estão unidos ao serem incorporados em uma única narrativa, ou seja, a temporalidade da experiência de cada sujeito com o objeto está presente no relato. Em campo cada participante da pesquisa teve seu relato escrito e/ou gravado, conforme a autorização, assim como sua identificação e sua voluntariedade em falar de sua experiência vivida acerca do bairro.

É importante ressaltar que a pesquisa foi publicada de forma parcial no IX Congresso de Geografia da América Latina - AGE-AL, realizado em Toledo (ESPANHA), com a publicação de Resumo e de Comunicação. Mas, agora a pesquisa foi concluída com a complementação de dados obtidos empiricamente, referente ao declínio do bairro, a observação em campo dos imóveis, a consulta em determinadas fontes documentais, que instrumentalizaram a abordagem intensiva de cunho fenomenológico em Geografia.

\section{Abandono e Arruinamento dos Espaços Edificados}

A palavra abandono em língua portuguesa é o ato ou efeito de renunciar; deixar o lugar em que o dever obriga a estar (AURÉLIO, 2018). E pode se referir a deixar algo ou alguém, afastar-se ou desprezá-lo (PRIBERAM, 2018). A pesquisa não trata do abandono de pessoas, mas das pessoas que convivem em ambientes abandonados. Então, procuramos referências teóricas que analisam o ato do abandono de edificações em espaços urbanos na contemporaneidade. 
Nosso interesse, neste primeiro momento, é o de exemplificar pesquisas que estudam ambientes construídos abandonados ou em ruínas. Teoricamente, as ruínas são consideradas como um registro vivo das edificações de um lugar, conforme os elementos tipológicos e estruturais, onde é possível identificar a sua data de construção.

Quanto “a aparência é mais um aspecto que representa um estágio em que o edifício já não apresenta suas defesas como cobertura, portas e janelas" (DINIZ, 2014 p. 3). É possível observar a (Figura 1) esses aspectos, além da vegetação que se alastra pelas paredes, que poderão levar ao enfraquecimento de sua estrutura.

Figura 1 - Edificação em ruína no Jaraguá/Brasil

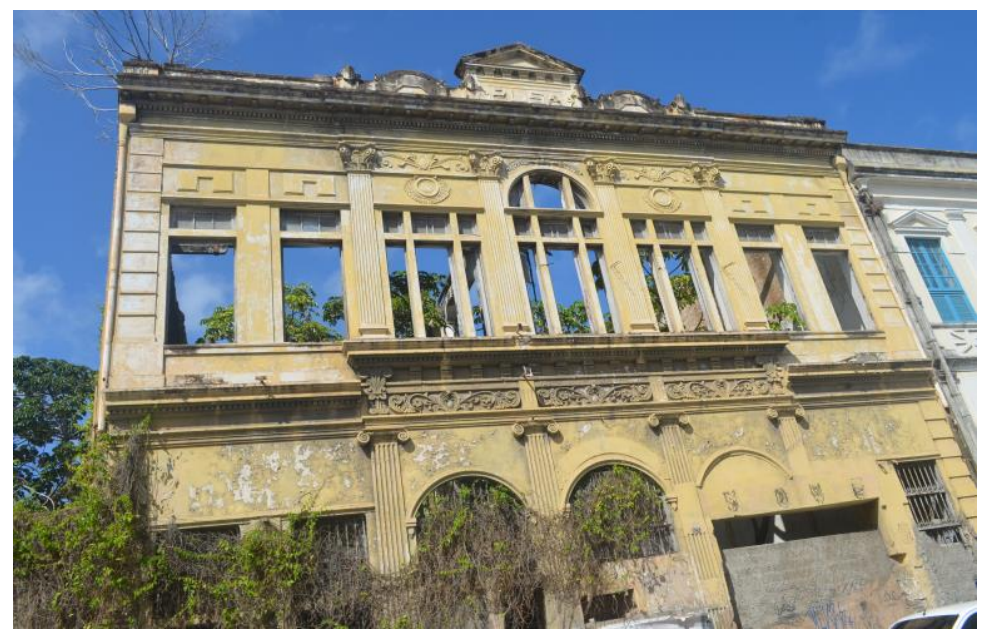

Fonte: SILVA, 2018

No Brasil conforme Diniz (2014, p.4) “as ruínas de todos os tipos de construção se espraiam por todo o país em áreas rurais e centros urbanos e são uma parte importante do nosso patrimônio nacional". Embora, os edifícios tenham “sobrevividos”, por dezenas ou centenas de anos, não vão resistir por muito tempo, caso não seja feito, ações de conservação ou restaurações.

A decisão de conservar ou restaurar nos remete a um debate teórico antigo na literatura, sobretudo para arquitetos e urbanistas. Assim, de forma introdutória destacamos a concepção do francês Viollet-le-Duc (1814-1879) e a concepção do inglês John Ruskin (1819-1900), considerado o principal teórico da preservação na Inglaterra do século XIX. Trata-se de concepções divergentes, quanto a conservação das edificações. Na contemporaneidade têm influenciado pesquisadores e ações de 
planejadores urbanos. Para Viollet-le-Duc “restaurar um edifício não é apenas preservá-lo, repará-lo ou remodelá-lo, é trazê-lo de volta a um estado completo tal que ele talvez jamais tenha estado em nenhum dado momento" (VIOLLET-LE-DUC apud CUNHA, 2010 p. 23). Para Viollet-le-Duc a restauração mantém vivo a edificação. Esta ação não pode ser vista como algo mecânico, mas como uma ação que exige conhecer a estrutura para dá-lhe vida novamente.

Para Ruskin "restaurar um edifício era tão impossível quanto ressuscitar um morto e que o passado expresso nos edifícios se equipara as ruínas" (MENEGUELLO 2008 apud DINIZ, 2014 p. 5). Assim, esta concepção entende que não há uma alternativa para preservar ou não os edifícios antigos, que não se trata de uma questão de conveniência ou simpatia. Acredita que os homens do presente não têm direito de tocá-los, já não os pertencem, os edifícios pertencem àqueles que construíram e as gerações futuras (MONTEIRO, 2018).

Segundo Diniz (2014 p. 5) “os franceses atingem efetivamente a memória histórica enquanto os ingleses chegam apenas à memória afetiva e piedosa" do ato de conversar ou não as edificações. Os estudos realizados por DeSilvey e Edensor (2013, p. 466) mostram o "interesse acadêmico por ruínas e espaços abandonados, sobretudo na última década". Explicam que o fenômeno do abandono ocorre em diferentes lugares, onde espaços geográficos de naturezas diversas estão sujeitos a esse abandono, como: bairros que caíram em decadência; fábricas que foram fechadas; centros comerciais abandonados; campos de testes militares experimentais e silos de mísseis abandonados; minas e pedreiras, estaleiros, armazéns e refinarias; hospitais, ilhas abandonadas etc., como uma característica de muitas cidades em todo o mundo.

De forma específica, citamos o trabalho de Lars Meier (2012) que analisa a classe social na perspectiva da Geografia emocional. A partir de entrevistas de história de vida com ex-metalúrgicos, analisa o senso de identidade e os sentimentos de perda que experimentam quando encontram a antiga indústria, desativada em 2002, na Baviera (Alemanha), cujas ruínas industriais são consideradas como metáforas de uma transição. (MEIER, 2012). A análise toma como referência as memórias de metalúrgicos que experienciaram tais transformações em sua vida profissional. Considera as ruínas da fábrica como um resultado inevitável do capitalismo, em que as ruínas, transformadas pelo tempo, detêm informações sobre mudanças na política econômica e nas estruturas sociais. 
Noam Leshem (2017) também associa o abandono às mudanças na política econômica. Embora voltado para o abandono de pessoas, a abrangência de sua obra permite refletir desde o banimento de Adão e Eva do Éden aos clichês de imagens fotográficas de Detroit, do século XXI. Pensa o abandono como uma temática central na cultura ocidental, sobretudo, de um determinado modelo econômico, já anunciado na obra de Friedrich Engels, em que destaca o abandono na Inglaterra:

Engels descreve famosamente como as paisagens industriais da Inglaterra são assombradas pelo abandono como consequência direta da reorganização capitalista da sociedade e espaço, mas também permanece atento à multiplicidade de forma que o abandono leva: aponta para o abandono das fazendas, tecendo os camponeses, os campos abandonados incorporados em grandes fazendas, os distritos históricos e casas abandonadas e ruínas na sombra de fábricas, e a escola deserta à noite originalmente destinada a crianças trabalhando nas fábricas (LESHEM, 2017 p. 623) ${ }^{2}$.

A explicação comum a Meier (2012) e a Leshem (2017) é o fato de considerar as mudanças econômicas como uma das causas do abandono. Nesse sentido, o abandono e o arruinamento podem ser considerados como parte de um dos movimentos descritos por Brito-Henriques (2017), ocasionado pela deslocação do espaço com a migração, a mudança de empresas, a nova rota do capital ou até mudanças no plano econômico e outros. O fato é que "alguns destes movimentos refletem mudanças estruturais" (BRITO-HENRIQUES, 2017 p.257). E o vestígio desses diferentes movimentos reflete na paisagem construída, nos espaços em abandono e em arruinamento, imposto pelo progresso e aceleração do tempo. Os dois fenômenos, arruinamento urbano e abandono, podem ocorrer de forma simultânea ou,

pode acontecer que o arruinamento se inicie com os edifícios ainda ocupados, vindo o abandono a dar-se em consequência do avanço da degradação; outras vezes acontece o contrário: a deterioração do edificado é espoletada e progride depressa após um abandono (BRITOHENRIQUES, 2017 p. 254).

Em particular no bairro Jaraguá, o arruinamento se manifestou de forma lenta, condicionado pelas ações econômicas e culturais, uma vez que o arruinamento pode ocorrer tanto de forma rápida, quanto de forma lenta. Quando de forma rápida, os eventos são causados pelos fenômenos da natureza (enchentes, terremotos etc) ou

\footnotetext{
${ }^{2}$ Noam Leshem, 2017 p.623
} 
intervenções humanas bruscas, como exemplo: o conflito na Síria, que levou a maior cidade do país às ruínas, em quase dois anos de guerra civil. Já no arruinamento lento, a ruína se dá de forma gradual, marginalizada por transições sociais ou econômicas, ou gradualmente o abandono vai se manifestando. Assim, a ruína pode atuar como um grão mais fino e, eventualmente, pode produzir ausências, como terrenos vagos e a negligência na infraestrutura (DESILVEY; EDENSOR, 2013).

O fato é que olhar as edificações em abandono ou em arruinamento conduz a maneiras pelas quais as qualidades materiais proporcionam experiências afetivas ou emocionais. A paisagem do Jaraguá expressa de forma objetiva a relação dos sujeitos com seu espaço exprime uma paisagem que apresenta, de forma descontínua, o abandono e o arruinamento, pontuado por vivência e atividades comerciais, levando a examinar essa relação entre os moradores e os espaços edificados.

Para examinar as condições dos imóveis em abandono, considerou-se a concepção de Hiller et ali (2003, p. 93), que aponta três características distintas relacionadas: a funcionalidade do imóvel, a situação financeira e o estado físico do imóvel, todas sendo de responsabilidade do proprietário em regularizar os serviços mantidos, tais como: energia eléctrica, abastecimento de água, estado de conservação do imóvel e o serviço de correspondência postal.

O abandono dos espaços edificados não se reduz a simples constatação de que uma propriedade está vazia, pois não indica a condição financeira ou física do imóvel. No entanto, as edificações em estado de abandono e arruinamento também podem ser identificadas pelo estado de conservação e de possibilidades de uso do edificado.

Pensar nossas experiências efetivas, sem pressuposições derivadas de qualquer teoria de base filosófica ou científica, permite distinguir entre a experiência da percepção real e a experiência da imaginação. Assim, o ato de perceber, mostra que a experiência que temos nunca é de uma "sensação atomística", mas pode expressar uma parte de um mundo, que vemos o que significa que "o caráter dessa parte é afetado por suas relações com outras partes do mundo. O mundo é experimentado, de forma inesgotável”. (MATTHEWS, 2011 p.43).

Para exemplificar essas relações, de forma mais específica, atentando para as edificações citamos Pallasmaa (2011) no livro “Os olhos da pele”, ao pensar que: 
uma experiência de arquitetura significativa não é simplesmente uma série de imagens na retina. Os "elementos" da arquitetura não são unidades visuais ou gestalt; eles são encontros, confrontos que interagem com a memória. Em tal memória, o passado é corporificado nas ações. Em vez de ser contida separadamente em algum lugar da mente ou do cérebro, ela é um ingrediente ativo dos próprios movimentos corporais que completam determinada ação (PALLASMAA, 2011, p. 60).

A arquitetura mostra a experiência do lar, estruturada por atividades distintas diárias de cozinhar, comer, socializar, ler, guardar, dormir, ter atos íntimos e não somente por elementos visuais. Esclarece que uma edificação ela é “controlada; abordada, confrontada, relacionada com o corpo de uma pessoa, explorada por movimentos corporais, utilizada como condição para outras coisas” (PALLASMAA, 2011 p. 60). Podemos entender que a arquitetura pode ser o ponto inicial, que orienta a direção e organiza o comportamento e o movimento de uma sociedade.

0 aporte conceitual do abandono e do arruinamento acerca dos espaços edificados ajuda a entender a relação objeto e sujeito, cuja questão principal é compreender como os sujeitos convivem num ambiente marcado pelo abandono, que contextualiza o ato de habitar no bairro. Para Claval (2011), o conhecimento que as pessoas têm dos lugares muda qualitativamente o comportamento de suas ações. Essa é a questão central de pensar acerca do conhecimento das pessoas ou de como as pessoas que moram ou trabalham experienciam ou representam o abandono e 0 arruinamento. 
Narrativas do declínio: Jaraguá ontem e hoje

Mapa 1 - Brasil, Alagoas, Maceió e Jaraguá

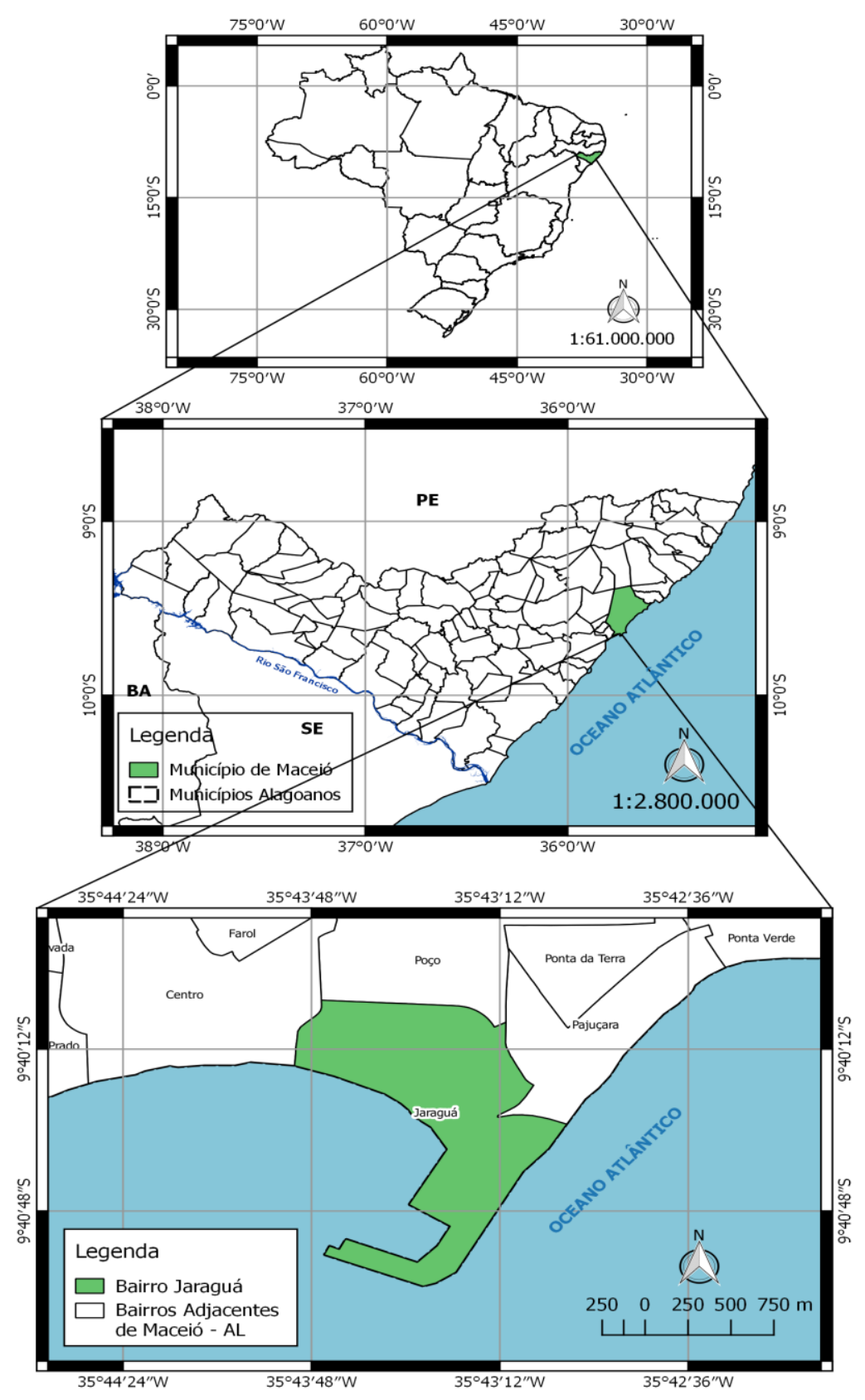

Fonte: MACEIÓ, 2018

As narrativas do declínio do bairro Jaraguá (Mapa 1) são constituídas de relatos gravados, obras escritas e jornais acerca do Jaraguá, com destaque para as obras de Espindola (1871); Costa (1932); Brandão (1909) entre outras publicações recentes de artigos acadêmicos e matérias de jornais. Ainda consideramos as discussões acerca do declínio urbano ao fazer referência aos estudos realizados por Lang (2005); Glaeser e 
Gyourko (2005); e Cesarino (2013).

0 processo de ocupação do bairro é visto como uma totalidade que pode ser constituído de pedaços e momentos. Os pedaços são partes que podem ser vistas de forma desagregada. Interessa-nos apresentar o bairro como momentos que são partes que não podem subsistir ou ser apresentados separadamente do todo ao qual pertence (HUSSERL, 2012).

Assim, o abandono e o arruinamento no Jaraguá são constituídos por determinados momentos, que destaco aqui como forma de termos uma visão de totalidade, pois são momentos que reúnem eventos que não se separam do contexto do abandono. Estão divididos em três momentos: a natureza do Jaraguá; Jaraguá: porta de entrada e saída; e Jaraguá declínio e abandono. Esses momentos, permitem compreender a contextualização do fenômeno.

A natureza do Jaraguá favoreceu o estabelecimento de um ancoradouro em sua volta (BRANDÃO, 1908). A cultura pesqueira, de acordo com Costa (1983) e Pedrosa (1998), situava-se na enseada do Jaraguá, onde os pescadores viviam da atividade pesqueira e formavam uma pequena comunidade em meio às atividades portuárias. Em relato, afirma Ramos (2018) “Jaraguá foi quem fez Maceió nascer, o porto do Jaraguá é um porto natural, Deus dotou o Jaraguá como porto, já era chamado de porto muito antes".

O Jaraguá como porta de entrada e saída de pessoas e mercadorias possibilitou a fixação de edificações formadas por casarões, sobrados, armazéns (trapiches), praças e igreja, situadas no coração do primeiro sistema de transporte portuário (a ponte de desembarque), ferroviário (via férrea) e rodovias (Figura 2) da cidade, que possibilitaram as condições necessárias para concentrar os estabelecimentos comerciais, residenciais e os serviços da época, levando a cidade a tornar-se a capital do Estado em 1839 (ESPINDOLA, 1871). 
Figura 2 - Jaraguá ontem

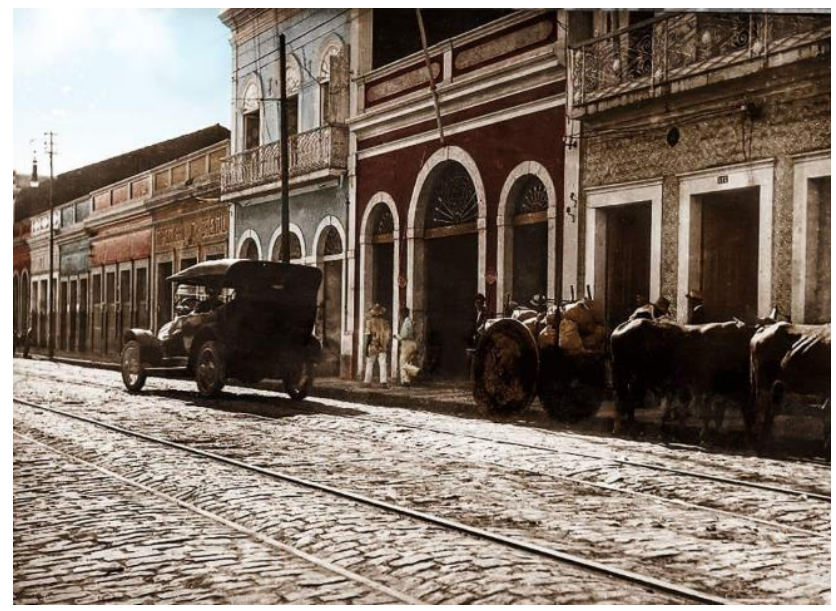

Fonte: arquivo público (2017)

No século XVIII, a unidade espacial próxima ao Porto era formada pelas Freguesias: Maceió, Jaraguá e Pioca. Estima-se que a população em 1860 da freguesia de Jaraguá era de 2.298 habitantes entre pessoas livres e escravos (ESPINDOLA, 1871). A instalação do porto ampliou a comercialização a exportação das mercadorias, devido às condições favoráveis de navegação, sobretudo após a inauguração da ponte de embarque em 1870, tendo sido posteriormente construídas mais 10 pontes de embarque, com apoio de americanos e da família dos Leões (LESSA, 2018).

$\mathrm{Na}$ atividade agrícola, o governo português decidiu investir na produção de algodão, para reduzir a dependência dos tecidos ingleses. Em Alagoas, isso fez com que o algodão ficasse mais interessante do que o açúcar. O Diretor do Museu afirma que: "muita gente acabou com seus engenhos para trabalhar com o algodão, até porque o Agreste e o Sertão plantavam algodão, era plantado geralmente pelas famílias, era um produto muito abrangente socialmente, então com isso é... deu impulso à cidade de Maceió" (Informação verbal, 2018) ${ }^{3}$.

Infelizmente, a fabricação de tecido foi proibida no Brasil em 1785, exceto, os grosseiros usados em roupas de escravos, sacos e fardos. Outros obstáculos também se impõem para as exportações, que nada tinham a ver com as questões políticas e militares internacionais. Referem-se à "má qualidade do produto brasileiro, misturado a folhas e a outras impurezas" (COSTA; BUENO, 2004 p. 19).

Contudo, a movimentação do Porto em 1869 registrou 190 navios e os gêneros

3 Benedito Ramos Amorim Diretor do Museu do Comércio de Alagoas 
de exportação: algodão, açúcar, couro e mel. A Praça de Pedro II e a ponte de desembarque constituíam o ponto mais frequentado da província e neles os navios ficavam abrigados. O Jaraguá, durante esse período, só crescia enquanto força econômica e cultural, marcado pela vida portuária intensa. Lembra-nos Lessa (2018) que as operações de carga e descarga realizadas apenas por botes e barcos de apoio atracados em trapiches, sendo o principal desses, a ponte de embarque que foi inaugurada em 1870. De acordo com os relatos de Fonseca (2018),

[...] Jaraguá foi o primeiro bairro de Maceió, era onde tinha aquela parte econômica, a renda portuária, os armazéns, os trapiches, e a localização dele perto do porto, isso também fazia com que a economia girasse ali, todos os navios de container, até os próprios turistas quando chegavam era o primeiro bairro que encontravam ao sair do porto (INFORMAÇÃ̃ VERBAL, 2018) ${ }^{4}$.

No Brasil, em 1919, a indústria têxtil nacional respondia por $75 \%$ a $80 \%$ da produção de tecidos de algodão consumidos no Brasil (COSTA; BUENO, 2004). Os efeitos positivos da economia algodoeira movimentaram a vida portuária, e o Jaraguá passou a ter uma maior expressividade, sobretudo com a instalação de bancos, armazéns (trapiches), comércios e cabarés.

$\mathrm{Na}$ década de 1980, a história da cultura do algodão no Brasil, com evidências de declíno, teve mais um grave problema, com o aparecimento da praga do bicudo, que praticamente transformou as plantações do Nordeste em terra arrasada. Em Alagoas, o declínio da cultura tem efeitos avassaladores como relatou Diretor do Museu do Comércio de Alagoas:

[...] esse crescimento você vai ver que aconteceu até o declínio do algodão, embora o açúcar tivesse continuado, mas houve o declínio do algodão (..) muitas fábricas de tecidos, muitas tecelagens, aqui mesmo nós tínhamos no Fernão Velho, nós tínhamos em Rio Largo, nós tínhamos aqui na Saúde, tínhamos em Delmiro Gouveia, tivemos em Penedo, então todas essas tecelagens fecharam, então isso fez com que Jaraguá declinasse (INFORMAÇÃO VERBAL, 2018) ${ }^{5}$.

O Jaraguá declínio e abandono, um processo que se dá de forma lenta, envolve um conjunto de ações que não estão isoladas, pois cada uma tem implicações diretas ou indiretas com o arruinamento do bairro. Aqui destacamos que a inauguração do

\footnotetext{
${ }^{4}$ Luciana Fonseca coordenadora do projeto Jaraguá Vivo

${ }^{5}$ Diretor do Museu do Comércio de Alagoas Benedito Ramos Amorim
} 
porto ocorrida na década 1940, com as novas instalações para armazenar o carregamento de açúcar, levou à desativação da ponte de embarque, que perdeu rapidamente a serventia econômica e, em 1943, inicia-se o processo de sua desativação total (LESSE, 2018).

Entre as décadas de 1940 e 1970, a implantação do cais terminal açucareiro e do cais comercial desativou a função dos trapiches (armazéns) situados em quase todo o bairro Jaraguá, sobretudo na rua Sá e Albuquerque. Nem todos os proprietários dos armazéns (trapiches) conseguiram manter suas instalações funcionando ou adaptá-las a novas funcionalidades. As novas instalações de acostagem do Porto contam hoje com: Cais de fechamento (destinado à atracação de embarcações de apoio marítimo); Cais comercial (carga geral, graneleiros e de passageiros); Cais de múltiplo uso, Cais do terminal açucareiro; Pier do terminal de granéis líquidos (LESSE, 2018). No relato de Fonseca (2018)

os armazéns deixaram de funcionar, digamos assim, apesar de que ainda existam, mas eles deixaram de ter a função previamente estipuladas para eles. A atividade portuária de armazenamento é gigantesca, dentro do porto tem os galpões enormes que armazenam açúcar, arroz e farinha (INFORMAÇÃO VERBAL, 2018) ${ }^{6}$.

Os sinais do arruinamento e do abandono estão mais evidentes na década de 1980, com problemas de infraestrutura, transportes e serviços. As más condições de tráfego na maioria das ruas e o declínio econômico das famílias manifestaram-se pela falta de conservação das edificações e bancos arruinados. No relato de Guerreiro (2018) explica que:

a saída de alguns usos básicos, como escolas que aqui foram fechadas, isso recentemente, a própria igreja católica que você não tem mais celebrações por já não ter mais gente residindo no bairro. Então, você não tem coro para ter uma celebração, a retirada também da Vila dos Pescadores foi um fato que diminuiu a movimentação do bairro (INFORMAÇÃO VERBAL, 2018) ${ }^{7}$.

Para (LANG, 2005) o declínio não tem uma causa única, forças de natureza diferente influenciam o declínio urbano. Como exemplos: o fim da exportação do algodão, a redução da população que decresceu 23,8\% nos últimos censos, sobretudo com a remoção da antiga vila dos pescadores, que implicou no fechamento da Escola

\footnotetext{
${ }^{6}$ Luciana Fonseca coordenadora do projeto Jaraguá Vivo

7 Thalianne de Andrade Leal Guerreiro técnica da Casa do Patrimônio - IPHAN
} 
Estadual Ladislau Neto e da Igreja de Nossa Senhora Mãe do Povo por falta de fiéis, evidenciam o fracasso da revitalização do bairro (1990/2000) entre outros eventos que levaram ao arruinamento do Jaraguá hoje.

\section{Experiência em Ambientes Abandonados e Arruinados}

A primeira parte trata da constituição das narrativas daqueles que moram e trabalham no bairro Jaraguá, que permite conhecer como os sujeitos se relacionam, pensam e até sentem os espaços abandonados ou arruinados. Na segunda parte destacamos as proposições de vivências em espaços abandonados no bairro Jaraguá, ações pensadas pela Prefeitura Municipal de Maceió e outros segmentos da sociedade que estão preocupados com o uso e as condições de conservação e preservação.

Mapa $n^{\circ}$ 02: Imóveis abandonados no bairro Jaraguá

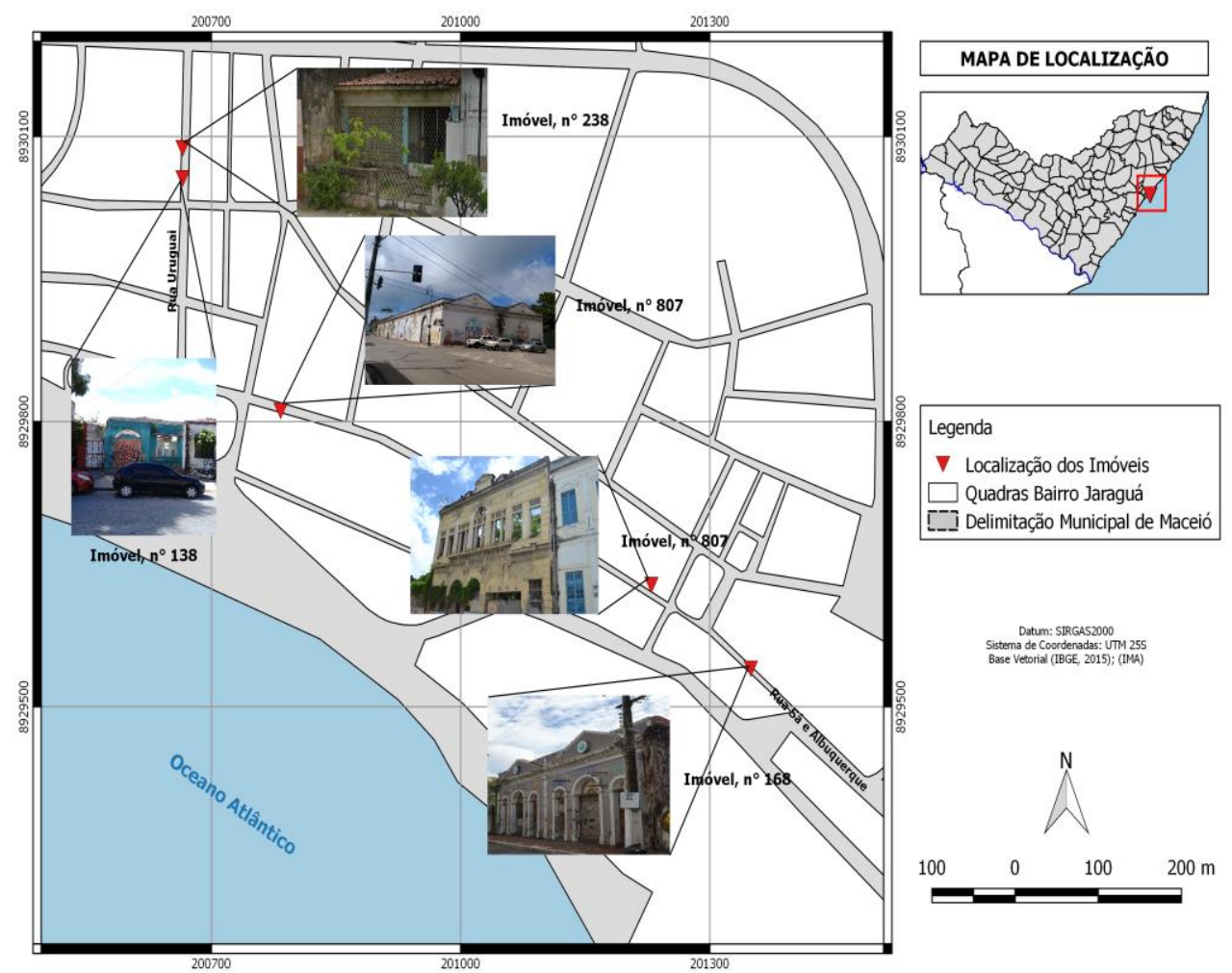

Fonte: IBGE adaptação SILVA, 2018.

As narrativas dos moradores das ruas Uruguai e Sá e Albuquerque (Mapa 2) e daqueles que trabalham no bairro possibilitaram compreender as experiências relacionadas aos ambientes abandonados e o significado para cada sujeito, pensando enquanto espaço vivido. Na verdade, as formas de narrativas expressas são relatos, 
testemunhos, falas interpessoais e conversas do cotidiano, sendo algumas gravadas e outras escritas. Não se trata de um simples registro, mas de interpretações contínuas e reinterpretações presentes no cotidiano, caracterizadas por serem fenômenos construtivos e reconstrutitvos, envolvendo exclusões, abreviações e reordenamentos do ato de pensar (ZAHAVI, 2017).

A compreensão das modalidades narrativas no contexto do abandono e arruinamento leva a discorrer sobre a intencionalidade dos interlocutores no processo de produção do real sentido. Os estados de coisas do mundo vivido contidos nos discursos da narrativa que envolvem: "crença, temor, esperança, desejo, amor, ódio, dúvida, alegria, riso, tristeza, orgulho, perplexidade, fantasia e imaginação, todos orientam determinadas fala de intenção do sujeito". (MOTTA, 2013 p.20).

A pesquisa reuniu pequenos trechos do discurso, de forma convergente ou diferenciada, para conhecer como cada um interpreta ou reinterpreta o lado obscuro do abandono, pois, às vezes, pode causar-lhe perigo, privação, medo e ansiedade. Desse modo, a compreensão da relação dos sujeitos com o objeto possibilitou refletir o significado, a experiência e a manifestação do fenômeno no bairro. As narrativas são complementadas e contextualizadas com outras narrativas presentes em documentos, revistas, jornais e publicações vinculadas em meios eletrônicos. Enfim, esse conjunto compõe o quadro das narrativas do bairro.

A compreensão das modalidades narrativas vinculada ao estado de coisas do mundo vivido, contido nos discursos, pode conceituar-se enquanto contágio emocional, o que significa ser o outro capaz de sentir a mesma emoção (ZAHAVI, 2017 p.154). 0 contágio emocional constitui a forma mais primitiva de empatia em que $o$ mimetismo é um de seus mecanismos centrais (DARWALL, 1998, apud ZAHAVI, 2017). É observado nas narrativas dos moradores em destaque:

"hoje Jaraguá é um bairro destruído, os prédios tudo aí velho, podendo fazer uma reforma, né, não, tão tudo estragado aí, abandonado" (INFORMAÇÃO VERBAL) ${ }^{8}$;

"os prédios tudo caindo, o que fizeram com o nosso pelourinho foi uma maquiagem, passaram uma massa para escorar, mas tá tudo caindo". (INFORMAÇÃ̃O VERBAL) ${ }^{9}$;

"hoje em dia as pessoas foram saindo, morreram os mais velhos e os mais novos foram morar em apartamentos, mais seguros, né" (morador 3 de 40 anos)

\footnotetext{
${ }^{8}$ Morador 1 de 20 anos

${ }^{9}$ Morador 2 de 30 anos
} 
"Jaraguá é um bairro mal falado, dizem que é lugar de prostituição, gay, bandido" (INFORMAÇÃO VERBAL) ${ }^{10}$;

"acho que o Jaraguá ficou um pouco abandonado porque não se divulga e nem incentiva para conhecer aquela região mais pra lá (rua Sá e Albuquerque) e a violência também fez com que diminuísse bastante o número de moradores". (INFORMAÇÃO VERBAL) ${ }^{11}$;

"só é ruim no final de semana, porque fica muito esquisito e tem falta de segurança" (INFORMAÇÃO VERBAL) ${ }^{12}$;

"hoje é muito esquisito, aí a gente pensa em vender a casa" (INFORMAÇÃO VERBAL) ${ }^{13}$;

"não vendi ainda essa casa porque não encontrei comprador, o bairro tá todo abandonado". (INFORMAÇÃO VERBAL) ${ }^{14}$;

"um bairro nobre, as casas abandonadas é um desperdício, a gente gostaria que voltasse os prédios de antes, uns prédios lindos desses e os donos deixam abandonado". (INFORMAÇÃO VERBAL) ${ }^{15}$;

"eu estou entrando com um processo contra a prefeitura de Maceió, eu sou estrangeiro, comprei esta casa porque achava que estava fazendo um bom investimento, perto do cais, um local tranquilo, um bairro histórico". (INFORMAÇÃO VERBAL) ${ }^{16}$.

O contágio emocional é o sentimento pelo qual você é infectado; consequentemente não é fenomenalmente dado como estranho, mas como seu próprio (SCHELER, 2008, apud ZAHAVI, 2017). Na verdade, no contágio emocional, quando se está infectado pela raiva, pânico ou jovialidade dos outros. As narrativas dos sujeitos permitem perceber o ato de experienciar, enquanto membro de um grupo ou melhor na condição de morador e/ou trabalhador de um bairro, que podem identificar-se com outros membros do mesmo grupo, e podem vir a ter experiência que elas não teriam de outro modo, mesmo se elas não estiverem efetivamente juntas de outras. Assim, cada sujeito tem em comum os espaços edificados em abandono no bairro, como um contágio motor, embora não se constitua como uma experiencia do nós, mas, de como o sujeito experiencia seu próprio sentir ou conviver no bairro. Assim sendo, os relatos odem traduzir melhor a forma como o contágio emocional é sentido pelos moradores, sem que com isso o sujeito tenha que compartilhar com o nós.

As narrativas dos que trabalham no bairro foram motivados pela questão de como eles percebem os espaços edificados com aspectos de abandono e de arruinamento no Jaraguá. A primeira a participar foi a moradora e proprietária de um

\footnotetext{
${ }^{10}$ Morador 4 de 20 anos

${ }^{11}$ Morador 5 de 27 anos

${ }^{12}$ Morador 6 de 12 anos

${ }^{13}$ Morador 7 de 15 anos

${ }^{14}$ Morador 7 de 40 anos

${ }^{15}$ Morador 8 de 20 anos

${ }^{16}$ Morador 9 de 10 anos
} 
espaço cultural chamado "La Rosa Mossoró" que fica localizado na Praça Arthur Ramos ou famosa Praça Rayol, no Jaraguá.

O sobrenome é conhecido há anos, em Maceió, vindo de seu pai, Benedito Alves dos Santos, chamado de 'Mossoró'. A fama surgiu nas décadas de 1970 e 1980, quando a boate e churrascaria Areia Branca, foi consagrada, na época como o melhor prostíbulo de Alagoas. Para Rosa de Mossoró, o Jaraguá pode ser revelado ao andar pelas ruas como se observa no seu relato:

Só você andar ali naquela rua do banco do Brasil, aí você vê logo tudo quebrado, você vai aqui depois do posto, passar a praça e a primeira à direita, o primeiro que você vê tá todo quebrado, você vê logo as ruínas, não precisa nem perguntar já vê as ruínas, em frente aquele prédio maravilhoso, a coisa mais linda do mundo...todo quebrado, ninguém faz nada, mas tem dono, todos os prédios aqui tem dono, ninguém imagine que não tem dono, que tem, muitos lugares com placas de aluguel e não alugar porque é caro, porque você não vai alugar um prédio desses por quatro, cinco mil reais por mês, como você vai pagar, num tem como tirar, quem tem dinheiro pode tirar...só sei que eu não posso, eu vivo aqui na luta porque meu espaço cultural [...] (INFORMAÇẤO VERBAL, 2018) ${ }^{17}$

A experiência de quem mora e trabalha no bairro mostra que os espaços edificados abandonados interferem até mesmo na perspectiva de investimento, pois não se trata de uma única rua ou de alguns prédios. Para Rosa de Mossoró há mais de uma rua com os imóveis abandonados e quando não, com placa de aluga-se (Figura 3). Afirma que todos têm proprietários, mas deixaram o imóvel se deteriorar. Ela guarda na memória a beleza que antes tinham, enquanto agora há ruínas como resíduo do passado.

\footnotetext{
${ }^{17}$ Rosa L. Bezerra dos Santos - moradora e comerciante
} 
Figura 3 - Imóvel para alugar

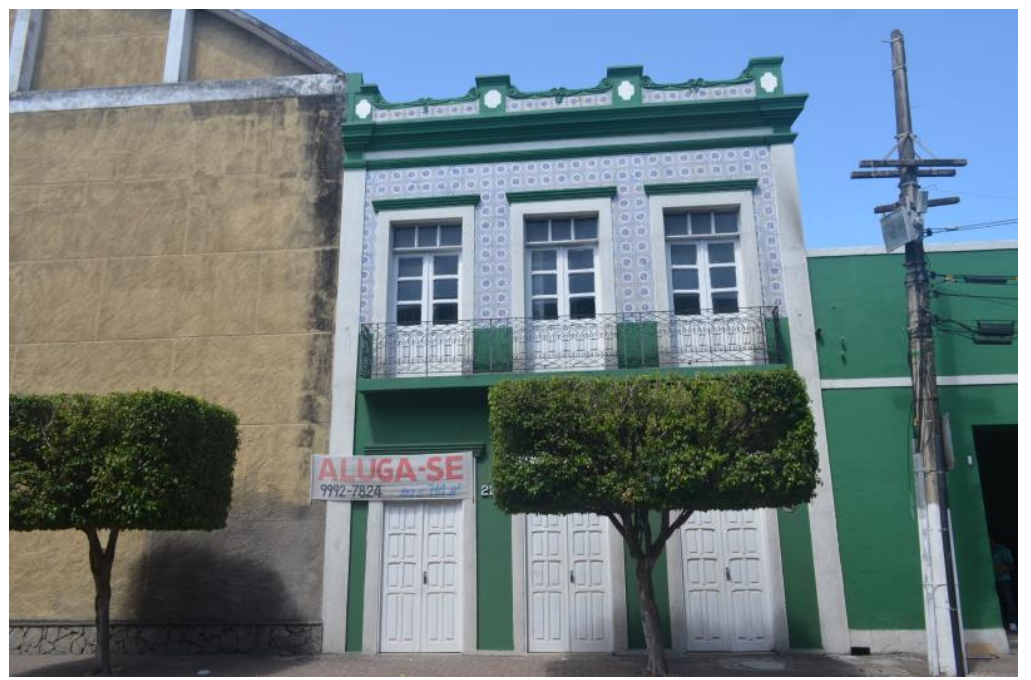

Fonte: Almeida 2018

A pesquisa contou com a participação do diretor do Museu de Imagem e do Som de Alagoas (MISA), criado em 3 de setembro de 1981, localizado na rua Sá e Albuquerque. 0 museu faz parte da estrutura funcional da Secretaria de Estado da Cultura (SECULT). O diretor Fernando Antônio Netto Lôbo, ao referir-se sobre ao abandono no Jaraguá, relatou que:

(...) isso é evidente, a gente observa essa situação de precariedade, muito embora normalmente se atribua ao poder público essa competência, mas a gente sabe que, em sendo uma área que é tombada historicamente, os proprietários dos edifícios são os responsáveis pela sua manutenção, né....Agora o bairro de Jaraguá historicamente sempre teve situações de altos e baixos. Desde que ele se constituiu ele esteve já em vários momentos em apogeu e agora em ruínas ou decadência. (INFORMAÇÃO VERBAL) ${ }^{18}$.

A narrativa expõe um contexto de abandono marcado pelas oscilações econômicas ocorridas no processo de constituição da ocupação do Jaraguá. O contágio emocional se dá pela visibilidade dos imóveis em situação de abandono, fato que não é recente e pelo qual os proprietários também são responsáveis. Na rua Sá e Albuquerque também está situado o Instituto do Patrimônio Histórico e Artístico Nacional (IPHAN), que é uma autarquia federal (13.01.1937) e tem a finalidade de proteger:

\footnotetext{
${ }^{18}$ Fernando Antônio Netto Lôbo Diretor do MISA

${ }^{18}$ Técnica do IPHAN da cidade de Maceió
} 
(...) os bens de natureza material e imaterial, tomados individualmente ou em conjunto, portadores de referência à identidade, à ação, à memória dos diferentes grupos formadores da sociedade brasileira, nos quais se incluem: I - as formas de expressão; II - os modos de criar, fazer e viver; III - as criações científicas, artísticas e tecnológicas; IV as obras, objetos, documentos, edificações e demais espaços destinados às manifestações artístico-culturais. V - os conjuntos urbanos e sítios de valor histórico, paisagístico, artístico, arqueológico, paleontológico, ecológico e científico. (BRASIL, 1988 p.4).

A instituição tem a finalidade de zelar pelo patrimônio brasileiro, sendo essa a principal razão para a criação do referido órgão. Na oportunidade, a técnica do IPHAN da cidade de Maceió, Thalianne de Andrade, nos relatou que:

[...] em relação a abandono ou ruínas no bairro Jaraguá, sim há algumas edificações que hoje estão sem uso, e a falta de uso é um dos condicionantes pra edificação em si ela ir degradando-se ao longo do tempo, são intempéries, é o vandalismo, enfim é um problema que não é corrigido que ao longo do tempo ele vai crescendo e só danifica a edificação. Bom... no meu entendimento, não há um conjunto de edificações em ruínas, há edificações pontualmente que estão arruinadas, os trapiches mais próximos da Praça Marcílio Dias que fica lá no final da Sá e Albuquerque, nós temos o banco de Londres também que é aqui próximo frente à Caixa Econômica (INFORMAÇÃO VERBAL, 2018).

A profissional atesta haver, sim, edificações que estão sem uso e em estado de degradação, ainda que isso ocorra de forma pontual e não em conjunto. Mas, é possível identificar na paisagem, esses imóveis que, realmente, não deixam dúvida sobre seu arruinamento.

Ainda na Rua Sá e Albuquerque, à altura do número 467, situam-se o Museu do Comércio de Alagoas e o Museu de Tecnologia do Século XX. Ambos funcionam no Palácio da Associação Comercial de Maceió, cujo prédio é uma referência histórica. 0 diretor e escritor Benedito Ramos esteve conosco e relatou sobre como o Jaraguá se apresenta, conforme sua experiência: “Então aí é o resultado do abandono. À proporção que há esse declínio, a própria associação comercial sofreu com esse declínio foi preciso ser restaurado tudo, mas se não ia cair, num é? Por quê? Porque essa movimentação aqui acabou (...)”. Para o diretor, o declínio das atividades econômicas, sobretudo das exportações com suas oscilações, é responsável pelo declínio do bairro e de toda sua funcionalidade. Em uma publicação do Jornal "O 
Palácio" da Associação Comercial de Maceió, Ramos (2016, p.06) afirma que a Casa Paroquial "lamentavelmente está em ruínas e aparentemente abandonada. 0 que faz do recanto lateral da igreja um espaço assombrado pelo abandono". O abandono é antes de tudo, um sentimento coletivo que se expressa pelo vazio.

As narrativas de cada sujeito mostram em perspectivas diferentes que 0 abandono e o arruinamento estão presentes no cotidiano do bairro. Esses ambientes, para alguns, chegam a causar medo, raiva, tristeza e, sobretudo um sentimento de perda, não só daquilo que já foi um dia o bairro, mas a perda das pessoas que partiram e que deixaram o vazio. É notável no discurso o fato de que as edificações em abandono representam algo negativo e com fortes implicações em decidir se devem permanecer ou partir para outro lugar.

\section{Proposições: Intenções e Ações}

A última parte do artigo destaca algumas narrativas que relatam propostas planejadas que revelam intenções e ações, sendo a primeira referente aquelas que estão apenas no campo das ideias, que demonstram o reconhecimento da importância do bairro e até denotam um grau de interesse e preocupação.

Primeiramente o Plano Diretor aprovado pela Lei $\mathrm{n}^{\circ} 5.486 / 2005$ e o Código Municipal de Urbanismo e Edificações instituído pela Lei $n^{\circ}$ 5.593/2007 Art. 51 . Definem o Jaraguá como um Zona Especial de Preservação 1 (ZEP-1 Jaraguá), entre os setores constituídos, destacamos o “Il - Setor de Preservação Rigorosa 2 (SPR-2), constituída por ruínas, edificações isoladas e/ou conjuntos antigos isolados situados na (ZEP-1 Jaraguá), cujas características deverão ser mantidas, obedecendo a rígido controle de intervenções, com base nas mesmas diretrizes do SPR-1" (MACEIÓ, 2006, p.25)

A concepção do Plano Diretor mostra claramente a influência conceitual de Ruskin, quando defende "a manutenção das ruínas e não sua restauração, a sua conservação tal como se encontra no presente, sob a ação do tempo e a ação depredatória humana, o que sustenta uma postura preservacionista" (NEMER, 2014 p.3). As ruínas como um espaço edificado para investigação científica, permitindo estudos avançados da sociedade local, olhando a ruína como memória e herança do passado.

Para os gestores da cidade a ruína deve ser mantida, é o que consta no Art. 51, 
mesmo que não signifique uma segurança para seus moradores, como relatam em suas narrativas. Insatisfeitos com o bairro precisam acreditar em mudanças, em dias melhores, capazes de superar o abandono, o vazio das ruas e, sobretudo, a insegurança de morar no bairro.

A proposta da Associação Comercial de Maceió foi de solicitar o tombamento da rua Sá e Albuquerque ao Instituto do Patrimônio Histórico e Artístico Nacional (IPHAN), através da Superintendência de Alagoas. Apesar de possuir tombamentos municipal e estadual, não asseguram a proteção do bairro, por essa razão, a Associação Comercial reconhece a importância das edificações de estilos arquitetônicos históricos, principalmente aquelas que estão situados na rua pleiteada, onde funcionavam bancos, armazéns, casarões entre outros (AMORIM, 2018).

Apesar de ter sido contemplado, na gestão da Prefeita Kátia Born (1996 - 2000), com o Projeto de Revitalização, com recursos advindos do Programa de Desenvolvimento do Turismo no Nordeste (PRODETUR-NE), não houve avanços. Entre alguns de seus principais objetivos, estava o incentivo ao turismo e à melhoria das condições de vida da população local. A rua principal, a Sá e Albuquerque (Figura 5), voltou a ser a mais movimentada do bairro e uma das mais frequentadas pelos residentes da cidade. No entanto, o bairro entrou no século XXI com os sinais nítidos de que o processo de revitalização não obteve sucesso (Araújo \& Vasconcelos, 2014).

Uma das manifestações do fracasso do Projeto de revitalização é sentida no declínio do número de habitantes. Ao contrário dos moradores, a gestão municipal tem mostrado interesse em ocupar o bairro, como relata o Diretor do Museu:

A gente está apostando numa retomada e recuperação dessa área porque o ente municipal, no caso, a prefeitura, tem projetos de requalificação da ocupação desse espaço, é tanto que a prefeitura, no final do ano passado (2017), ela se instalou aqui no Jaraguá, e também tá trazendo muito de seus equipamentos, e...secretarias e os demais órgãos para aqui, para realmente estimular a ocupação dessa área, né... e há um projeto de estimular é por parte do empresariado para atividade privada ser desenvolvida aqui, também a gente sabe que o governo do Estado também tem um projeto de desenvolvimento dessa área, criando um polo de tecnologia da informação. Tem a perspectiva, desse ano, a inauguração desse espaço aqui, centro pesqueiro que vai de alguma forma estimular, inclusive até a vinda do turismo é através das rotas dos cruzeiros. (INFORMAÇÃO VERBAL, 2018) ${ }^{19}$

\footnotetext{
${ }^{19}$ Diretor do Museu Benedito Ramos Amorim
} 
Figura 4 - Rua Sá e Albuquerque no bairro Jaraguá

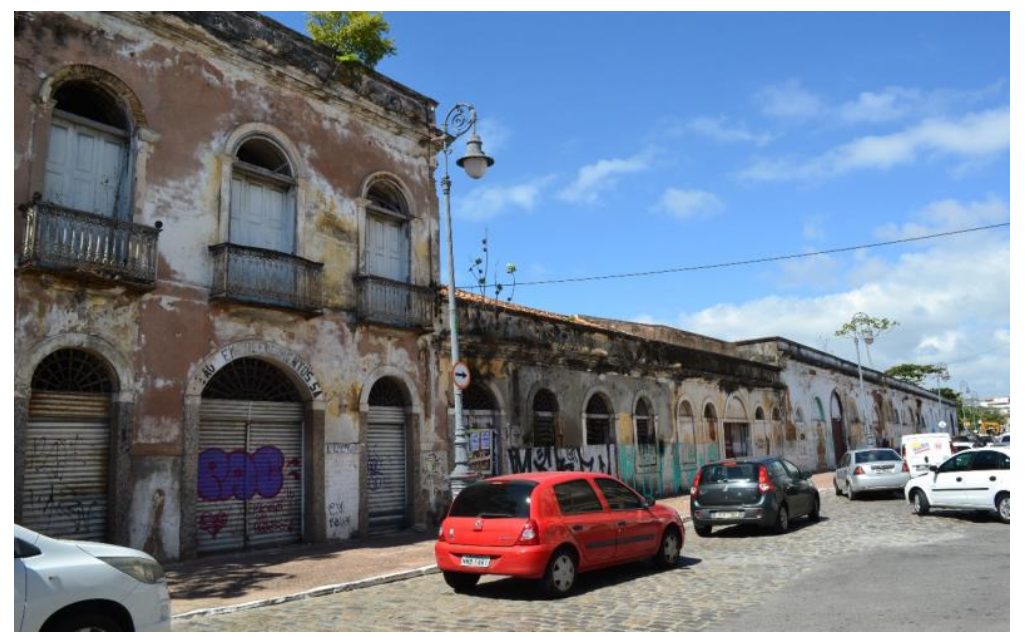

Fonte: SILVA. 2018

As ações futuras dos governos municipal e estadual visualizam estimular o desenvolvimento do bairro, como exemplo o prédio centenário onde funcionava a Escola Estadual Ladislau Neto (desativada em 2016), recebeu a proposta de funcionar como uma escola de formação para o Corpo de Bombeiros, ainda está em avaliação pela Secretaria de Educação (Ascon, 2016). Contudo, são projetos que não consideram os antigos moradores e não pensam nas qualidades emocionais (GOLDMAN APUD CESARINO, 2013).

É oportuno citar a iniciativa do “Projeto Jaraguá Vivo" desenvolvido pela Secretaria Municipal de Promoção do Turismo (SEMPTUR), com a iniciativa de realizar passeios turísticos pelo bairro. O roteiro cultural e histórico revivendo o Jaraguá começava no Arquivo Público de Alagoas, passava pelo Instituto do Patrimônio Histórico e Artístico Nacional (Iphan), Igreja Nossa Senhora Mãe do Povo, Sindicato dos Estivadores, Praça Dois Leões, Museu da Imagem e do Som de Alagoas (MISA), Fundação Teotônio Vilela e Associação Comercial de Maceió. (FONSECA, 2017).

De acordo com a Coordenadora do Projeto o objetivo era de ser um atrativo, uma peça nova de atrativo cultural na cidade, ele não veio pra resgatar o bairro, ele não veio pra revitalizar o bairro, ele veio pra ser um atrativo cultural a mais na cidade. Infelizmente, “os locais não estavam disponíveis para abrir toda sexta começaram a se cansar, eu acho, os próprios museus, a igreja, então tinha dia que os visitantes iam e um local desse, estava fechado, e aí já estava perdendo um pouco da atração, acho que realmente ouve um desgaste pelo tempo" (FONSECA, 2017). 
Mais um projeto que não obtém sucesso, o que se torna indiferente para moradores que não notam problemas no bairro, admitindo gostar de morar, enquanto existem moradores que identificam os problemas, responsabilizam moradores e governo pelas edificações em abandono. A ponto de manifestar propostas, como é o caso da comerciante do bairro que relata que se deve "revitalizar Jaraguá com prédios, vamos fazer moradias, vamos fazer o pessoal morar, façam um lugar que tenha artista..." (MOSSORÓ, 2018).

Aqueles que se preocupam em cuidar da imagem do bairro para o turista, na verdade, estão ligados às intenções do processo de revitalização, alvo de críticas, principalmente no tocante aos efeitos observados na rua Sá e Albuquerque. Contudo, alguns moradores reconhecem o valor do bairro, como relata o morador da residência 298: “como este é um bairro histórico, aproveitando que tem toda essa historicidade, deveriam aproveitar mais, hoje falta muita segurança”. Como não chega aos moradores o que pensam os gestores da cidade, observe, no relato da técnica do IPHAN, o planejamento das ações administrativas para os imóveis no Jaraguá:

Infelizmente esses imóveis a maioria são de propriedade particular, são privados, então não tem como a gente pensar soluções, porque somos orgão público, é no caso a gente conhece já ouvi falar que alguns proprietários estão buscando projetos para recuperação de seus imóveis né... porque Jaraguá, desde de setembro 2017, recebeu a prefeitura, isso é um dado muito recente. Então o gabinete do prefeito e outras tantas secretarias estão no bairro, porque a prefeitura municipal está enxergando o Jaraguá, aliás está enxergando o planejamento da cidade a partir das discussões do Plano Diretor que tá em revisão de que as áreas de urbanização consolidadas elas têm que ser reocupadas. Isso é o Jaraguá, o centro e outros bairros também que têm o foco muito comercial durante o dia e não têm uso residencial forte. Então o Jaraguá foi escolhido para ser a sede da prefeitura e desde, então, eles estão tentando construir instrumentos normativos que facilitem o acesso a empresários né...para ocupar aqui o bairro. Alguns já têm seus imóveis e outros estão tentando comprar, também alugar, enfim espaços. Então é uma tentativa de criação de benefícios de redução de impostos, IPTU, ISS, redução ou isenção, enfim aí vai depender muito do que está dentro da lei. (INFORMAÇÃ̃O VERBAL, 2018) ${ }^{20}$

No contexto dos diálogos narrativos as pessoas residentes não sabem o que planeja o governo. 0 fato é que a falta de vivência no bairro e o abandono tanto pelo comércio quanto pelos moradores são sentidos de forma expressiva em cada morador,

${ }^{20}$ Técnica do IPHAN da cidade de Maceió 
pois os espaços construídos encantam os olhos, sendo vistos como belos, uma lembrança de glória do passado, que causa simpatia àqueles que ainda amam morar no bairro, mesmo com os problemas identificados e da responsabilidade das autoridades (governo) e da sociedade.

\section{Considerações finais}

A paisagem do abandono para os moradores e trabalhadores do bairro Jaraguá se manifesta de forma diferente. Há sujeito que pensa a partir de sua vivência, de sua experiência como os espaços construídos, às vezes, apresentam-se próximos aos objetos reconhecendo sua importância e sua historicidade; outro, às vezes, distanciase como se os objetos fossem parte do problema, ou não estivessem ali.

0 discurso mais comum nas narrativas foi a falta de vivência no bairro, aspecto relevante no processo de arruinamento do bairro Jaraguá, que vem acontecendo desde sua constituição, marcado pelas oscilações econômicas e culturais. Enquanto processo, o arruinamento só pode ser revertido a partir de um planejamento urbano que envolva todos os cidadãos. Não se trata de uma obra única do poder administrativo, como já se teve como exemplo a revitalização no final da década de 1990, que considerou a atração turística como carro chefe da mudança.

As narrativas sinalizam por parte dos sujeitos a preocupação, a esperança, a revolta e o medo de morar em ambientes abandonados. 0 eu e o nós se juntam em termos de relação com o mundo. Não há um sujeito que não reflita sobre as consequências a partir de sua vivência, tanto aqueles que moram, quanto aqueles que trabalham. A forma como o mundo se apresenta, manifesta no sujeito a dúvida e a esperança provocadas pelo contágio das edificações abandonadas ou em ruínas.

0 trabalho consultou moradores, técnicos, diretores, empresários e outros que têm formas de pensar e agir diferentes. Então, esse é o formato que deve estar presente nas propostas de intervenção, como instrumento principal do Planejamento urbano, que não seja o esforço de um órgão, mas que crie mecanismo de participação envolvendo todos, pois a diversidade e a sensibilidade emocional de quem vivencia o bairro devem ser consideradas. Do contrário, estamos, mais uma vez, fazendo um esforço unilateral para "resolver" situações problemas, sem fazer com que as pessoas sintam-se parte do projeto.

A tecnologia permite abrir vários canais de comunicação para os gestores ouvir 
e envolver a sociedade com os seus problemas que não são de responsabilidade única do gestor, mas somos todos corresponsáveis pela vivência no bairro. Pensar o bairro para aqueles que moram, primeiramente, e não para aqueles que estão de passagem, como os turístas, seria o ponto mais importante a ser considerado em um novo projeto de revitalização, ou melhor, um Projeto de vivência em edificações abandonadas.

Hoje, o Jaraguá significa para moradores espaços abandonados, ambientes favoráveis para a ação de assaltantes, para a prática da prostituição e para a venda e o uso de drogas. 0 medo de caminhar pelas ruas do bairro toma conta do habitar em meio às edificações em abandono, revelam-se expectativas negativas com o ambiente construído através das narrativas, mostrando que o abandono carrega questionamentos de um futuro incerto para os presentes e para os "ausentes".

\section{Referências}

ARAÚJO, L., VASCONCELOS, D.A.L. Espaço Público “Revitalizado" e Contradições: Enobrecimento e Antienobrecimento no Bairro de Jaraguá, Maceió-AL. Revista Turismo \& Desenvolvimento, 2014, vol. 3, №21/22, p.411-422

AURÉLIO. Dicionário Aurélio. [online]. 2018. Disponível em: https: / / dicionariodoaurelio.com/abandono.

BRANDÃO, M. Histórias de Alagoas. Penedo. Artes Graphicas. Typ. E. Pautação. 1909. BRITO-HENRIQUES, Eduardo. Arruinamento e regeneração do espaço edificado na metrópole do século XXI: o caso de Lisboa. Revista Latinoamericana de Estudios Urbano, 2017, vol. 43, N¹28, p.251-272

BRITO-HENRIQUES, E. Corpo, Pessoa e Espaço Geográfico: repensar o humano na Geografia Humana. In: Centro de Estudos Geográficos da Universidade de Lisboa. Geophilia. O sentir e os sentidos da Geografia. Lisboa, 2007, p.113-128.

CERBONE, David R. Fenomenologia. Rio de Janeiro, 2ª . Ed. Trad. Ceasar Souza: Vozes, 2013.

CESARINO, Gabriela. Estudos de Caso de Requalificação Urbana nos EUA: Goldman Properties. Uberlândia - IV Colóquio Internacional. Sobre Comércio e cidade: uma relação de origem. 2013. Disponível em : file:///C:/Users/Gil/Downloads/GOLDMAN\%20REVITALIZA\%C3\%87\%C3\%830\%20EUA.pdf CLAVAL, P. A Geografia Cultural. Florianópolis: Editora da UFSC. 2007.

COSTA, Sérgio Rodrigues; BUENO, Miguel Garcia. A saga do algodão: das primeiras lavouras à ação na OMC. Rio de Janeiro:Insight Engenharia, 2004

COSTA, Craveiro. Alagoas em 1931. Maceió: Ticianeli, 1932. Disponível em: https://www.historiadealagoas.com.br/wp-content/uploads/2017/02/Alagoas-em1931-menor.pdf

CUNHA, Claúdia dos Reis, 2010. Restauração: diálogos entre teoria e prática no Brasil nas experiências do IPHAN [online]. Tese, Faculdade de Arquitetura e Urbanismo, Universidade de São Paulo. [viewed 13 março 2018]. Available from: 
http: / / www.teses.usp.br/teses/disponiveis/16/16133/tde-26052010-090302/pt-

br.php

DESILVEY, C. y EDENSOR, T. Reckoning with ruins. Progress in Human Geography, 2013, Vol. 37, N . 4. Disponível em: https://doi.org/10.1177/0309132512462271

DINIZ, Luciana Nemer, 2014. Projetos contemporâneos em ruínas: o passado compartilhado no presente. III Encontro da Associação Nacional de Pesquisa e Pósgraduação em Arquitetura e Urbanismo. Arquitetura, cidade e projeto: uma construção coletiva. 2014. Disponível em: https://www.anparq.org.br/dvd-enanparq3/htm/Artigos/ST/ST-PCl-007-4.pdf

ESPINDOLA, Thomaz do Bom-Fim. Geographia alagoana, ou descripção physica, política e histórica da província das alagoas. Maceió: Typographia do Liberal . 1871. Disponível na Internet em https://digital.bbm.usp.br/handle/bbm/6731

GAZETA. Jornal, 2016. Projeto de revitalização do bairro de Jaraguá. 2016. Disponível em: http: / /gazetaweb.globo.com/gazetadealagoas/noticia.php?c=283024

GIL, Carlos, Antônio. 0 projeto de pesquisa fenomenológica. Anais IV SIPEQ - ISBN 978-85-98623-04-72012. Disponível em: https://arquivo.sepq.org.br/IVSIPEQ/Anais/artigos/44.pdf

GLAESER, Edward L., Gyourko, Joseph,2005. Urban Decline and Durable Housing. Copyright The University of Chicago Press. Reprinted from Journal of Political Economy, 2005, Vol.113, No. 2. Disponível em: http://repository.upenn.edu/penniur_papers

HELLER A. E. et al. Predicting Housing Abandonment with the Philadelphia Neighborhood Information System. Published in Journal of Urban A airs, 2003, Vol. 25, No.1, 91-105. 2003. disponível na internet:

https: / /repository.upenn.edu/cplan_papers/7/

HUSSERL, E. Investigações lógicas. Investigações para a fenomenologia e a teoria do conhecimento. Rio de Janeiro, Forense, 2012.

HUSSERL, E. A ideia de fenomenologia. Trad. Arthur Morão. Lisboa: Edições 70, 1989. IBGE, Instituto Brasileiro de Geografia e Estatísticas. Características da população e dos domicílios: resultados do universo. 2010. Disponível em: https: / / censo2010.ibge.gov.br/

LANG, Thilo. Insights in the british debate about urban decline and urban regeneration. Leibniz-Institute for regional development and structural planning (IRS) 2005. Disponível na Internet:

http://www.irs-net.de

LESHEM, Noam. Spaces of abandonment: Genealogies, lives and critical horizons. Durham University, UK Environment and Planning D: Society and Space. 2017, Vol. 35, No.4, 620-636. Disponível em: https: //mc04.manuscriptcentral.com/societyandspace LIMA, C. Histórias do Duque de Jaraguá. Recife: Edições bagaço, 2005.

MACEIÓ. Código de Urbanismo e edificações de Maceió. Diretoria do Plano Diretor. Maceió/ Alagoas. 2006

MAH. A. Industrial ruination, community, and place. Landscapes and legacies of urban decline. University of Toronto Press. Toronto Buffalo London, 2012

MARANDOLA JR. Eduardo. Fenomenologia e Pós-fenomenologia: alternâncias e projeções do fazer geográfico humanista na geografia contemporânea. Revista Geograficidade, 2013, vol.3, №2, p.49-64.

MENEGUELLO, Cristina. Da ruína ao edifício: neogótico, reinterpretação e preservação do passado na Inglaterra vitoriana. São Paulo: Analume; Fopesp, 2008.

MEIER, Lars. Encounters with haunted industrial workplaces and emotions of loss: class-related senses of place within the memories of metalworkers. Cultural 
geographies, 2012, Vol.20, No. 4. Disponível em: https: / / doi.org/10.1177/1474474012469003

MOTTA L. G. Análise Crítica da Narrativa. Brasília: Editora Universidade de Brasília, 2013.

MONTEIRO, F.A. John Ruskin: teorias da preservação e suas influências na preservação do patrimônio brasileiro no início do século XX. $3^{\circ}$. COLARTES Arte, Cultura Distrações Antagonismos. 2012. Disponível em: file:///C:/Users/Gil/Downloads/7641-17582-1PB\%20(1).pdf.

PALLASMAA, J. Os olhos da pele: a arquitetura e os sentidos. Porto Alegre: Bookman, 2011. 76p.

PEDROSA, J.F.M. História do velho Jaraguá. Alagoas, Ed. Talento. 1998

VIOLLET-LE-DUC, Eugène Emmanuel. Restauração [Restauration]; tradução de KÜHL, Beatriz Mugayar. Cotia, SP : Ateliê Editorial, 2006.

ZAHAVI, Dan. Você, eu e nós: o compartilhamento de experiências emocionais. Researchgate, 2014. Trad. Gabriel Henrique Dietrich. Disponível em: https://www.researchgate.net/publication/276366515. 